\title{
The Ability to Learn and Ability to Teach: Learning and Teaching Styles
}

\author{
Elena A. Bogomolova \\ Department of Developmental \\ Psychology and Education \\ K.E. Tsiolkovskiy Kaluga state \\ University \\ Kaluga, Russia \\ kviip@yandex.ru
}

\author{
Irina V. Gorelova \\ Volgograd Institute of \\ Management at the Russian \\ Presidential Academy of National \\ Economy and Public \\ Administration \\ Volgograd, Russia \\ iri25100@yandex.ru
}

\author{
Mariam R. Arpentieva \\ Department of Developmental \\ Psychology and Education, \\ K.E. Tsiolkovskiy Kaluga state \\ University \\ Kaluga, Russia \\ mariam_rav@mail.ru
}

\author{
Menshikov P.V. \\ Department of of Developmental \\ Psychology and Education, \\ K.E. Tsiolkovskiy Kaluga state \\ University \\ Kaluga, Russia \\ edeltanne@list.ru
}

\begin{abstract}
The article is devoted to revealing the role of the teacher in the development of creative potential of students: matching skills to teach and the ability to learn, their reflection in didactic communication. Teaching ability assumes the successful transfer of learning skills to learners: a deep and versatile understanding of oneself, the interlocutor and the studied fragment of the objective world: creating conditions for a multifaceted and multilevel comprehension of knowledge and skills by students. The ability to learn implies an orientation toward understanding the teaching material in the context of didactic communication with a particular teacher and fellow students in a specific historical and cultural context.

Keywords- ability to teach, ability to learn, teaching communication, forms of communication, modes of communication, understanding
\end{abstract}

\section{INTRODUCTION}

The modern system of education and upbringing undergoes multiple external and internal transformations. This is creating a special request for the ability of students and learners to learn, as well as the ability of teachers, mentors to teach and to optimize didactic communication, integrating and adapting a variety of traditional and innovative forms of teaching and education to specific historical and cultural contexts of pupils' development. Thus, the leading issues of education and upbringing are the issues of the ability to learn and teach. The main aspects of these abilities are those related to styles, features and technologies of teaching and learning activities. The problem of styles of learning and, a little, of learning styles, is sufficiently broadly covered in both Russian and world theory and practice. In the Russian and soviet research, cognitive styles and styles of teaching / learning were investigated by such researchers as A.V.
Karpov, I.M. Skityaeva, P.V. Menshikov, A.E., Steinmetz, and others. In the word research, the problem of cognitive styles of learning was studied by B. L. Liver, F. Marton, N. Entvistl, D. Kolb, and others [1]. One of the most actively developed areas of research is the ability to learn and teach, involving the wide participation of psychological and psycholinguistic knowledge and practical technologies learning a foreign language [2]. Active developments in this area are being conducted in the national school, including in the research school of G.V. Rogova, emphasizing the importance of didactic communication between the teacher and students in the process of mastering the language knowledge and skills. The development of didactic communication occurs in the direction of reproductivereproducing, familiarizing-explanatory and monologic forms of the teacher's influence on the pupil to creative and developing interaction aimed at re-understanding knowledge and skills, himself and the world in the dialogue between teacher and student. Didactic communication of persons who are able to teach and learn is the process of translation, understanding (understanding) by subjects of interaction of knowledge, skills, and values of educational and professional activities. Didactic communication is the formation and development for the success (self) learning and (self)teaching of psycho-technologies and meta-knowledge, to transform and apply the most optimal styles of teaching and learning. The aim of the research is the development of an integrative model of didactic communication as a developing system of learning and teaching ability components.

Objectives of the study:

- Theoretical analysis of the problem, development of an integrative model of didactic communication as a process of personal comprehension of the academic and professional situation (tasks); 
- Theoretical analysis of the concepts of the ability to learn and the ability to teach in the context of ideas about didactic communication and the styles of teaching and learning activities.

Object of the research: structure and content of didactic communication of teaching and learning, possessing different skills to learn and teach.

The subject of the research: modes, possibilities and limitations of didactic communication in the interaction of teaching and learning with different styles of teaching and learning.

As the main hypotheses of the study, the assumptions were made that:

1. Features of didactic communication are related to modus (orientation): teaching, learning, self-learning, mutual learning / mutual teaching. Didactic communication in different modes is aimed at the formation and development of various types of teaching and learning. Ability to teach assumes a successful transfer to the learners the ability to learn: a deep and versatile understanding of oneself, the interlocutor and the studied fragment of the objective world. In different modes of didactic communication there are varying degrees and forms of the processes of transmission, retransmission and transformation of the skills to learn and teach (corresponding knowledge, skills, values, psychotechnologies and meta-knowledge).

2. Development of the ability and readiness of a multi-level and multilateral, dynamic and systemic understanding of the self and the world, the comprehension of the acquired knowledge, skills and properties in the context of such a holistic understanding is the leading condition for the formation and development of the ability to learn and the ability to teach. Thus, the building and development of the ability to teach and the ability to learn involves changing the types of understanding of oneself, the interlocutor, the situations of educational and professional activity, the world outlook in general.

The theoretical and empirical analysis of the relationship between the ability to learn and teach is shown in the article. The ability to learn and teach is related to the orientation of didactic communication on the development and selfdevelopment of students in the framework of group, joint and self-learning.

\section{DisCUSSION}

Modern, experiential, contextual learning models are aimed at managing the process of formation and development of the productive type of personality of the student and teacher. They also are aimed at transformation of the counterproductive type of personality and / or the correction of counterproductive aspects of personal and social functioning and development. Due to modern approaches and psycho-technologies there is a harmonization of processes of the education and training. There are processes of the optimization of the interaction itself. This optimization suggests the development of meta-competencies as the ability to teach and the ability to learn. These approaches and its psycho-technologies are aimed at preventing and correcting misunderstanding of self and the world, harmonizing the relations of subjects of didactical communication and pedagogical interaction in whole [1]. There is importance of a contextual, understanding approach to education, transforming life activity. Transdiscursive model of the education is placing the subject in the situation of comprehending the diverse object and personal discourses of the surrounding world. The role of understanding in modern didactic communication among other types of didactic communication is especially emphasized. Didactic communication is the communication of subjects about learning: its various components and processes. Understanding didactic communication is aimed at developing students' understanding of themselves and the world, as well as building mutual understanding between the teacher and students in the process of retransmission and cocreation of knowledge and skills in the joint activity of students, the teacher and (sometimes) the supervisor [3]. A communicative approach in didactics is one of the most promising $[4 ; 5 ; 6 ; 7 ; 8 ; 9 ; 10 ; 11 ; 12]$. The didactic situation determines the specifics of communication, reflection and orientation according to socially established prescriptions and / or mutual expectations of partners (teacher and pupils) [10; $13 ; 14]$. Thus, the features of didactic communication, including those expressed in the concept of "learning to teach", largely determine the direction of development of the learner's understanding and personality, including the ability of the student to learn. The activities of the teacher and the activities of the student are largely uninterpretative: therefore, the reversibility, personification and objectivity of communication are so important [15, p. 200-236]. B.L. Leaver identifies two main approaches to learning: "Western" and "non-Western" [16; 17]. Western approach means traditional orientation to logic and order, abstract - logical, verbal form of presenting information, consistent way of thinking. Therefore, students with a non-Western approach automatically fall into the "risk group": for children and adults of this type, de facto, the necessary conditions for development in didactic communication are not provided. A more well-known and curriculum-oriented classification is the classification of teaching styles according to Kolb's theory [18]. According to his theory, two main parameters describe the behavior of a person in the process of learning. Each of these parameters has two opposite poles. The first parameter reflects the way of interaction with educational information that can be processed either at the level of direct interaction with objects (active experimentation) or at the level of observation of these objects (reflexive observation). The second parameter reflects how a person comprehends the learning content: in the form of concrete experience or in the form of abstract concepts (abstract conceptualization). Bipolarity of the selected parameters means that their poles are mutually exclusive: a person can act at any particular moment in time, or observe, comprehending the situation, specifically or abstractly. D. Kolb created a method based on combines the psychological types suggested by K. Jung and his school, the assimilation and accommodation processes 
described by J. Piaget and other system models, such as the $\mathrm{K}$. Levine field theory as well as the functional and pragmatic J. Dewey's model. K. Levine regards life as a process of recentering and decentralization. J. Dewey is the authors of the ideas of democracy and intersubjectivity in learning, situational success, and so on. [19]. According to D. Kolb, there are four cyclically organized stages of educational activity. First, the student, interacting with the learning situation, accumulates a concrete experience, second, he begins the stage of reflexive observation of what is happening, and the results of this observation are comprehended in abstract concepts, which are verified by direct interaction with the object. Because of the experiment, a new experience appears and the cycle begins anew [18]. The aspects described by him are overall consistent with studies of educational and teaching activities that are traditional for Russian psychology $[20 ; 21 ; 22]$. As scholars note, the stability of the styles of teaching and learning, the preferences of styles, remains relatively constant for every person $[9 ; 22 ; 23]$. The idea of styles as individual ways of perceiving, preserving, reproducing educational information enables the gap between the teacher and the student. The idea of styles making them equal in rights. This idea focuses on understanding other participants in the learning process; each has different features of working with information. But often there is a so-called conflict of styles - a discrepancy between style of the Teaching the teacher and the style of the student's learning $[17 ; 24 ; 25]$. What the teacher expects from his students in the lesson is based on his own preferences in the field of teaching, in the choice of the style of instruction. And when these preferences do not coincide with the educational preferences of students, the preferred styles of teaching, there is a conflict of styles. As soon as the teacher changes the teaching style to meet the needs of students and / or demonstrates the advantages of other styles, helping to change the preferences in choosing a style of educational activity, the conflict is resolved. Knowing your own and others' strengths and weaknesses of cognitive activity, similarity and difference in it, teachers and students can achieve maximum effectiveness of their interaction, satisfaction with their relationships and communication, processes and results of their teaching and learning activities $[9 ; 26]$. In the process of preparing, it is necessary to create conditions for the formation and transformation (enrichment of style "palette") of personal styles of teaching and learning. At the same time, students and educators with different styles of teaching and learning should be able to choose "lines" (approaches) of teaching and learning according to their style characteristics, but within a single educational space. Simultaneously, it is necessary to create and develop the necessary educational environments for further enriching this "palette" of each teacher and student (in the framework of both teaching and extracurricular activities, didactic and nonautodidactic communication), honing the merits of different styles. Thus, the task of taking into account the individual styles of students in the learning process is transformed into the task of forming and transforming a personal set of styles (as well as managing the styles and communication with the world). This task is the (trans)formation and development of the meta-knowledge and meta-abilities (skill) to learn and teach. These processes is one of the aspects of a holistic education, directed on personal development and realization. Formation of the personal style of the student and the teacher involves different basic requirements. It involves the identification of the available style preferences of the given student and the teacher (groups of teachers and students), the study and awareness of the "weak" and "strong" sides of this type of style behavior both by the child himself and by the teacher. It involves the creation of conditions for actualization of cash styles at all levels of style behavior and didactic communication; research and improvement of basic features and mechanisms of style behavior at each level; style integration as an enrichment of the style characteristics of didactic communication, teaching and learning activities. The teacher must be aware of situations in which students with different style features of the teaching will have difficulty in mastering the teaching material. Different problems in learning and teaching related to the style of the teaching and learning activities, and to the features of the subject material in didactic communication. Some difficulties relate to the peculiarities of the style of peer education. In communication with other people takes place the styles assimilation, modify the traditional and innovative approaches and styles of the teaching in specific schools and universities. The focus on change, the creation of conditions for change is viewed as the essence of pedagogical activity, and the most important goal is the creation of conditions for the self-change of the student's personality [28]. In many respects, it is the reflection of ideas about oneself, the world, educational and training activity, ideas about it. Three kinds of beliefs affect the teacher's practice. These are a view of education, a look at learning and a view of the subject / science [29]. Teachers' beliefs significantly influence the formation of typological features of their teaching and are the link between the cognitive component (knowledge) and the activity component of teaching (teacher practice): persuasion is a kind of "bridge" between knowledge and skills, understanding and action $[30 ; 31]$. N. Noddings noted that to understand the pedagogical behavior of teachers and students it is important to understand their perceptions, experiences and beliefs concerning the subject and process of teaching [31]. The study of beliefs is especially important for changing the strategies of the teacher's activity in the process of innovation, with changes in standards and norms, in the transformation of programs and in the formats of teaching. Thus, the influence of constructivism has given rise to a new direction in research: the study of beliefs-beliefs of teachers and students. At the same time, as M. Pajares noted, studies devoted to this construct do not have separate convictions, teachers' and pupils' beliefs are inextricably linked with each other and with other beliefs about life and also with experiences and perceptions [32]. Teachers and students have many representations and experiences on which they rely and which they encounter in the framework of didactic 
communication, and which, in turn, rely on an even wider range of more significant life beliefs. Teachers and students have their activity and ability to learn and the ability to teach, are connected with the life experience of participants in didactic communication in general. The concept of "beliefs" and the concept of value-semantic orientations closer to Russian science, serves as the central concept characterizing the system of regulation of the structure of knowledge. Beliefs in didactic interaction are in the "twilight zone" between awareness and experience: they contain components from each of these areas. They are formed by stable objective, scientific and experiential or subjective (based on experience) explicit and implicit knowledge and skills of an individual about a particular discipline and its teaching / learning. Researchers sometimes distinguish between different kinds of beliefs. Thus, they call concepts the conscious value-semantic attitudes in teaching and learning, distinguishing them from beliefs. Beliefs are often unconscious. The belief system of an individual is closely intertwined with the system of his knowledge and skills, so that it is even difficult to consider these systems in isolation from each other. F. Furingetti and E. Pekonen note that knowledge and skills can be divided into objective and subjective. Beliefs should be considered primarily as subjective knowledge, while the components of their experience should be taken into account [33]. At the same time, referring to the tradition of studying beliefs, one can see that they are opposed to truth, objective knowledge and skills, which, of course, is not entirely accurate and causes asymmetries in the process of preparation and in the further activity of specialists. Teachers' and pupils' beliefs about teaching and learning include "traditional, direct transfer / appropriation of knowledge and skills, and " constructivist", aimed at building knowledge and skills by the students themselves through a teacher-organized activity, in dialogue with the teacher [34]. E. von Glasersfeld formulated two basic principles of constructivism: 1) Knowledge is not perceived passively, the cognitive subject actively constructs it. 2) The cognitive function is adaptive and serves to organize a given in the experience of the world, and not for the discovery of ontological reality [35, p. 16]. Constructivist teachers see students as active participants in the process of gaining knowledge and provide the student with opportunities independently and / or in dialogue with other students and the teacher to understand the solution of the problem / concept, etc. It is interesting in this sense that the subjective concept of teaching, marking. differences between declarative knowledge and procedural knowledge $[21 ; 36]$. The procedural nature of the subjective concept led to the abandonment of the traditional for the psychological and pedagogical works of describing it through the totality of its declarative knowledge, and the tacit assumption that there is sufficient knowledge that automatically means its application in the real situation of activity. On the contrary, there is a separate process of transforming declarative knowledge into procedures-procedural [36].

In Russian psychology, A.E. Steinmetz described a similar process. He described this process as the operationalization of concepts [28]. N.V. Kuzmin [20], believing that the criterion for resolving a series of tasks / completing the system of assignments is the advancement of the teacher and students towards the ultimate goal of activity, noted that some pupils and teachers have a substitution of finite goals for private ones. This kind of displacement of goals and deformation of values and meanings in activities lead to violations in the pedagogical process, in teaching and learning. E. Stones writes that teachers train in the use of individual skills without understanding the psychological and pedagogical basis of the educational process, which makes the acquired skills "blind" [24, p.17]. It is necessary to pay attention to the relevance of the subjective concept to the available psychological and pedagogical knowledge. Objective, scientific knowledge differs from other forms of knowledge (subjective experience) effectiveness: therefore. in the learning process, a reliance is needed on the approaches and methods of activity that have developed in science, and the knowledge and skill behind them is understood / appropriated only when it functions in the mind in a form that is adequate and specific for the expression of the given concept in the student science. Studies of the beliefs of teachers and students show that their beliefs are determined by school practice both their experiences as students in school, and the influence of colleagues, the school environment [37]. R. Philip notes the often "inconsistent" convictions, their inconsistency with the practice of teaching teachers and teachings from students, explaining this by the influence of "context" [38]. The task is to change the beliefs of teachers if they are at lower levels [37, p. 195]. The unfolding of didactic communication in the non-classical (modern) model of learning is not associated only with a clear and structured "communication of information", not only with contextual semantic repetitions. The unfolding of didactic communication in the non-classical model is associated with the work of understanding aimed at finding similarities and differences already understood and understood. The learner strives to make his knowledge and skills not only recognizable but also stimulating to creativity, "puzzling". Therefore, the activity of the student becomes interpretative in many respects: the text "presented" to the student is organized by the teacher to realize the intention of "obtaining information" and meets the principles of creativity and co-creation, as well as the rhetorical requirements of dissenter speech: the plurality of "new" and seemingly "wellknown" to the revision of both background and acquired knowledge and skills, everyday experience is problematized; students learn to disintegrate and compare, and also integrate and unite. The most important thing is not concretization, but generalization: the reversibility, personification and objectivity of communication is combined with its focus. On the search and implementation of the most general, integrative ideas about the subject under study; along with relative order, dissidence and its uncertainty are created as a regular stage of understanding didactic communication "noisy chaos", familiar to many researchers and practitioners on the procedures of "brainstorming", etc. (going beyond the boundaries of the logical and chronological sequence, free 
transitions from one component of didactic communication to the other and back, the use of open questions, paraphrases and silence, etc. [39, 40, 41, 42, 43, 44]. In addition to pedagogical and cognitive psychology, social psychology contributed to the development of ideas about communication. $[45,46,47,48]$ The work of social psychologists in the theoretical and applied fields is connected with the study of communications and the problems of communicative impact. They study the conditions of their productivity and effectiveness. They reveal the role of interrelations, which have or impede further educational and educational communication. Their work is especially important in conditions of uncertainty: didactic communication is a collection of continuing unanticipated situations with the educational and upbringing levels, transformations of these situations are closely related to the features of the didactical model. We believe that the study of didactic communication in the vein of the problems of the professional image of the world, understanding oneself and the world is one from the most productive aspects. As noted by one of the leading researchers of communication in our country L.A. Petrovskaya, and also Gia other researchers, competence in communication, which determines the success of communications, and therefore training, is determined by how a person knows and understands itself, the partner and the situation of interaction $[1 ; 47]$. Theoretical analysis of the problems of didactic communication allows us to conclude that in the integrative model of didactic communication as understanding communication, understanding is the leading focus and the task of both sides of the learning (learning) processes. The ability to learn and the ability to learn from the teacher and students are associated with the development and realization of their ability to understand themselves, each other and the world, the fragments of which become objects of didactic communication [1]. They include different levels of knowledge, skills and beliefs about oneself, each other, the subject as a part of reality and science, teaching and learning, as well as the didactic communication itself, its whole, models and values.

\section{RESULTS}

To understand means to comprehend unite into a single whole, to correlate a) the lokutive (subject-related, connected with a specific sphere of professional knowledge and skills), b) illocutive (aim-oriented, connected with the value aspect of interaction) and c) perlocutive (mutually and closely connected with the psycho-technological aspect of interaction) aspects of the communicative message, to correlate the message of the instructor (tutor, fellow practitioner) with similar substructures of his own communicative message (messages) (preceded by the second and subsequent). At the same time, as a result of the conscious and unconscious accumulation of knowledge and skills, psycho-technologies and values, as the personal growth and professional development of teachers and students / students develops, a regular and directed transformation of the modes of didactic communication and the types of training corresponding to them is carried out:

1) Teaching didactic. Didactic communication proceeds from the fact that the teaching of children and young people includes the movement from the learner to the taught. In a different measure, the recognized appropriation of knowledge and skills, teacher which refers to a greater or lesser depth and fullness, more or less unconscious psycho assignment and values related activities assignable domain-specific (but not professional-specific) knowledge and skills [42; 43]. The ability to learn is the ability to assign knowledge and skills. These knowledge and skills are logically structured and selected by those who have the ability to teach. Criteria of skills - external, performance of control tasks. Typically the implicit idea of the immediate pursuit of skills from knowledge, and explicit inability to use knowledge and skills, their "disintegration" after the next control point. Didactic communication is outwardly harmonious and successful, but internally conflict: children with "backlogs" and "run-ins" in development, with a special understanding of themselves and the world in communication with the teacher and fellow practitioners are uncomfortable. They aware of their differences as a sign of inefficiency and inefficiency (in relation to others and the subject or even the situation of the teaching as a whole).

2) Teaching didactic communication. The teaching of adults, including professionals, is aimed not so much at the appropriation of knowledge and skills, as in the formation and support of certain behaviors and attitudes of the learner, in ensuring the success of solving tasks (quasi) professional activities. At this level, the differently realized awareness of the transmission of knowledge and skills acting as supports for the organization and implementation (change) of activities, more or less realized broadcast and relaying of valuable psycho-technologies and meta-knowledge (quasi) professional activities that ensure the implementation of activities (real actions, transformation of the behavior of the subject) $[1 ; 44]$. The ability to teach involves a flexible approach to teaching, focusing on not only the appropriation of knowledge, but also the formation of real skills, the students' understanding of the essence of the taught. Learning also involves reflecting on learning and learning activities. Didactic communication is more harmonious and successful, effective and productive.

3) Self-learning didactic communication: in the process and the result of self-learning, a systemic transformation of teaching and learning activities takes place: a differently realized, in-depth and in-depth understanding of the components of educational and professional activity, its success, effectiveness and productivity comes into the center. The goal of the teacher is teaching the learning, i.e. changes in the educational, professional activity and life activity of a person teaching themselves on the basis of values that are mastered and transformed by them in the process of development, psychotechnologies and meta-knowledge, knowledge and skills of educational, professional and professional activities $[49 ; 50 ; 51]$. The ability to learn and 
the ability to learn acquire the status of the ability to change and change - to change external and internal activities. It is described by researchers as an important first step in becoming a person: "becoming a person", "becoming a professional", including, in terms of existential-humanistic psychology [41;43], or "self-efficacy", as described in the behavioral tradition) [52; 53].

4) Dialogic didactic communication is a reciprocal, largely conscious learning by people of each other. It transmits knowledge and skills in the sphere of transformation and management of professional and general life activity through the exchange of values and the transformation of values, psycho-technologies and meta-knowledge, knowledge and skills of productive and effective interaction that are interpreted as changing in relation to activity and in relation to the reality behind it the world). Didactic communication includes the whole range of relationships, including a dialogue about "beliefs": values and semantic activities, teaching and learning, knowledge and skills. Learning and teaching and related changes in life act as a leading aspect of life development, of subjects in general. Thus, mutual learning changes the studing of each other as individuals, changing their lives through the development of awareness (change) of themselves and the world. This state of "flow", "meeting", "becoming a partner", "co-being", "full functioning" is described in existential-humanistic psychology [54; 55], or the state of "effectiveness" - in the behavioral $[52 ; 53]$. The transformation of the teacher and pupil, their knowledge and skills, beliefs, is two-sided, although it is not completely symmetrical. At this level (the level of "superprofessional")- a person changes activities, creates new forms (and components that provide the activity) and renounces the old ones [1;41].

- As for the possibilities and limitations of various modes of didactic communication, in the reality of which all modes coexist in different proportions, depending on the level of personal, interpersonal and professional development of a person), its preparation. Efficiency and productivity of any kind and form of teaching and learning from the point of view of this choice depends on how the pedagogue understands his work, how the student relates to his own teaching, what role of educational and professional activity he assigns in his own life, what ways of teaching and learning available to him. Efficiency and productivity of teaching and learning depends on how developed their ability to teach and learn. Thus, the task of the teacher is the creation and maintenance of a developing and "psychotherapeutic-oriented" learning environment (facilitating environment) [40]. Researchers note the role of the "learning ability" as a system of components of "interpersonal intelligence" as human ability to interact with other people, and "intrapersonal intelligence" - as the ability to recognize oneself in the context of a holistic view of a person (interpersonal intelligence, intrapersonal intelligence) [1; 57]. If a teacher refuses educational tasks and is not capable of reflecting the processes and results of education, the latter destroy "out-of-contextness" and the teaching activity itself and didactic communication within the framework of this activity $[1 ; 9$, p. 10-13].

\section{CONCLUSION}

In general, the characteristics that distinguish effective educational relations from ineffective ones are: awareness of what knowledge people have, to which one can address questions (orientation); the opportunity to access this person in a timely manner (accessibility); the desire to take part in solving the problem and gaining knowledge (participation) and the degree of freedom of the relationship, conducive to learning and creativity (freedom) $[9 ; 51]$. The summary. There are many options for distinguishing learning styles and teachings that answer differently to the question of optimal conditions and the results of educational and training activities: emphasis is on mastering the main and reliance on logical judgments "against" the orientation toward unsystematic memorization and reliance on memorization; a generic or understanding approach or a reproductive and instrumental approach; a deep and versatile approach to the teaching material and an approach based on its detailed and simplified approach; transformative learning and reproductive education. many typologies of styles can not be unambiguously correlated with the skills to learn and teach, rather it deals with the possession of a palette of ways to comprehend the subject, the situation of its study and subjects of didactic communication, and also - in general, oneself and the world. However, many typologies also confidently move in the direction of differentiating styles that contribute to and hamper the formation and development of the ability to learn and teach. In the process of didactic communication, the ability to learn becomes a direct and general result of the ability to teach: trying to understand, a person moves along the path from "fact" to a dialogue with knowledge and skills, students and teachers, the world. The central recommendations for educators and students, professionals included in the procedures of mutual learning and selfeducation, can be recommended to $t$ to themselves and the world, include the postulate the idea that learning and learning is work associated with a multitude of processes and results that enrich the life of a person developing his relationship with himself and the world. To be able to teach and be able to learn means to be happy, harmonious, free, to develop. As B.L. Liver notes, ".. I came to the persistent conviction that all students, without any exception, can learn. They can learn foreign languages... They can learn to write correctly. The only thing they may not be able to do is to study as prescribed by a specific program, textbook or teacher" $[17$, p. 5]. That is why the psychological and methodological competence of the teacher is so important, the importance of which was written by G.V. Rogova [2] and many others scientists and educators.

\section{REFERENCES}

[1] M.R. Arpentieva, P.V. Menshikov "Didactic communication: the ability to learn and the ability to teach". Kaluga: Tsiolkovskiy Kaluga state University, 2017, 353p. 
[2] G.V. Rogova, F.M. Rabinovich, T.E. Saharova, "Methodology of teaching foreign languages in high school". Moscow: Prosveshhenie, 1991, 287 p. (In Russian)

[3] M. R Minigalieva, "Supervisor counseling: tricks and strategies of mutual understanding". Kaluga: Tsiolkovskiy Kaluga state University, 2012, 195p. (In Russian)

[4] V. Yu. Troitskiy, "Fates of the Russian school", in Problems of the Heritage of Russian Literature. Ed. O. A. Platonov. - Moscow: IRTs, 2010, 480p. (In Russian)

[5] V. I. Tyupa, "Analysis of the artistic text". Moscow: Academia, 2009, 336.p (In Russian)

[6] L. I. Gur'e, "Designing of Pedagogical Systems". Kazan' : Kazan state technol. university, 2004,212 (In Russian)

[7] V. S. Bibler, S. Yu. Kurganov, V. F. Litovskiy, "School of dialogue of cultures." Ed. by V. S. Bibler. - Kemerovo: ALEF, 1993, 416p. (In Russian)

[8] Yu. N. Emel'yanov, "Active social and psychological training". Leningrad: Leningrad state university Publ., 1985, 168p. (In Russian)

[9] M. R. Minigalieva, "Theaching-educational interaction: the ability to learn and the ability to teach". KhantyMansisk: Ugra state university, 2018, 32p.. (In Russian)

[10] M. Yu. Oleshkov, "Didactic communicative situation", in World of education - education in the world, 2008,1, pp. 182-194. (In Russian)

[11] G. P. Shchedrovitskiy, "Selected Works". Moscow: ShKP, 1995, 800p. (In Russian)

[12] P. G. Shchedrovitskiy, "Essays on the philosophy of education: articles and lectures". Moscow: Eksperiment, 1993, 15p4. (In Russian)

[13] M. Yu. Oleshkov, "Modeling of the communicative process". Nizhniy Tagil: Nizhnetagil state soc.-ped. akademia, 2006, 336p . (In Russian)

[14] N. Tamarchenko, «Aesthetics of verbal creativity» M. M. Bakhtin and Russian philosophic-philological tradition. - Moscow: Kulaginoy Publ., 2011, 400p. (In Russian)

[15] P. L. Soper, "Basics of the Art of Speech". Rostov : Feniks, 1999, 380p. (In Russian)

[16] B.L. Liver, "The method of individualized teaching to a foreign language, taking into account the influence of cognitive styles on the process of its acquisition: Dis. .. PhD in ped. sc.". - Moscow: Moscow state university Publ., 2000, 192p. (In Russian)

[17] B.L. Leaver, "Teaching the Whole Class". - London: Publisher: SAGE Publications, 1997, 230p.

[18] D.A. Colb, "Experiential learning: experience as a source of learning and development". Englewood Cliffs: PrenticeHall, 1984, 247p.

[19] J. D'yui, "Democracy and Education". - Moscow: PedagogikaPress, 2000, 384p. (In Russian)

[20] N.V. Kuz'mina, "Methods of studying pedagogical activity." Leningad. Leningrad state university Publ., 1970, 114p. (In Russian)

[21] D.A. Oshanin, "Subject action and operational image". Voronezh: NPO MODEK, 1999, 512p. (In Russian)

[22] N.F. Talyzina, "Theoretical Problems of Programmed Learning" Moscow: MGU, 1969, 132p. (In Russian)

[23] O. E. Mal'skaya, E. V., "Investigation of the influence of the style of teaching on the understanding of schoolchildren of educational texts", in Psychology of learning. Moscow, 2008, vol. 1, pp. 2938. (In Russian)

[24] E. Stouns, "Psychopedagogy: Psychological theory and practice of teaching". Moscow: Pedagogika, 1984, 472p. (In Russian)

[25] M.A. Kholodnaya, "Cognitive styles: On the nature of the individual mind". - Moscow: PER SE, 2002, 304p. (In Russian)

[26] K.A. Moiseev, "Interrelation of the subjective concepts of teaching and pedagogical goal-oriented at the teachers. Master's dissertation”. Kaluga: Tsiolkovskiy Kaluga state University, 2017, 93p. (In Russian)

[27] O.V. Rudykhina, O.S. Shemelina, "Ratio of intellectual styles and psychological types in the structure of the identity of students of the high school", in Bulletin of the Kursk state University, 2011, vol. 3, pp.263-267 . (In Russian)
[28] A.E. Shteynmets , "Psychological preparation for pedagogical activity". Kaluga: Tsiolkovskiy Kaluga state University, 1998, 308p. (In Russian)

[29] C. Hoyles, Mathematics teaching and mathematics teachers: A meta-case study. For the Learning of Mathematics, 1992, vol. 12(3), pp.32-44.

[30] A. G. Thompson, "Teachers' beliefs and conceptions: A synthesis of the research". In: D. A. Grouws (Ed.), Handbook of research on mathematics teaching and learning. - New York: Macmillan, 1992, pp.127- 146.

[31] N. Noddings, "Constructivism in mathematics education" in Davis R.B., Maher C. A., Noddings N. Eds.Constructivist views on teaching and learning mathematics. Reston, VA: National council of teachers of mathematics, 1990, pp.7-18.

[32] M. F. Pajares, "Teachers' Beliefs and Educational Research: Cleaning Up a Messy Construct", in Review of Educational Research, 1990, vol. 62, 3, pp.307-332.

[33] F. Furinghetti, E.Pehkonen, "Rethinking Characterizations of Beliefs", in Beliefs: A Hidden Variable in Mathematics Education? Eds G.C. Leder, E. Pehkonen, G. Torne. - Dordrecht: Kluwer Academic Publishers, 2002, pp.39-57.

[34] OECD, "Creating Effective Teaching and Learning Environments: First Results from TALIS". Paris: OECD, 2009, 90p.

[35] I. S. Safuanov, "Theory and practice of teaching mathematical disciplines in pedagogical institutes". Ufa: Magarif, 1999, 220p. (In Russian)

[36] D. Anderson Cognitive Psychology. St. Petersburg: Piter, 2002, 496 (In Russian)

[37] E.K. Pehkonen , “On Teachers' Beliefs and Changing Mathematics Teaching", in Journal fuer Mathematik-Didaktik, 1994, vol. 16, 3/4, pp. 77-209.

[38] R. A. Philipp, "Mathematics teachers' beliefs and affect", in Second Handbook of Research on Mathematics Teaching and Learning . Ed. F.K. Lester. - Charlotte, NC: Information Age, 2007, pp. 257-315.

[39] M. Csikszentmihalyi, "Flow: The Psychology of Optimal Experience." - New York: Harper Perennial Modern Classics , 2008, 520p.

[40] Rogers C. R. "On Becoming a Person: A Therapist's View of Psychotherapy". London : Mariner Books, 1995, 420p.

[41] Rogers C. R. "Becoming partners: Marriage and its alternatives." New York: Delacorte Press, 1972, 280p.

[42] Rogers C. R., Lyon H. C., Tausch R. On Becoming an Effective Teacher. - London: Routledge, 2012, 288p.

[43] C. Truax, \& K. Mitchell, "Research on certain therapist interpersonal skills", in A. Bergin \& S. Garfield (Eds.). Handbook of psychotherapy and behavior change. New York : Wiley, 2013. $864 \mathrm{p}$.

[44] Yu. M. Zhukov, "Training as a method of improving communicative competence: dis. .. grand $\mathrm{PhD}$ in psych. sc." Moscow: MGU, 2003, 356p.

[45] A. Yu. Panasyuk, "Psychology of rhetoric." Rostov : Feniks, 2007, 208p. (In Russian)

[46] L. A. Petrovskaya, "Competence in communication". Moscow: MGU, 1989, 216p. (In Russian)

[47] E.V. Sidorenko, "Training of communicative competence in business interaction".- St. Petersburg: Rech', 2006, 208 p.

[48] S. Hase, and C. Kenyon, "Self-Determined Learning: Heutagogy in Action". Bloomsbury Academic, 2015, 224p.

[49] S.Hase, and C. Kenyon, "Heutagogy: A Child of Complexity Theory", in Complicity: An International Journal of Complexity and Education, 2007, vol. 4 (1), pp. 111-118.

[50] G. Batson, "Mind and Nature: A Necessary Unity". - Lomdon: Hampton Press , 2002, 240p.

[51] A. Bandura, "Social Foundations of Thought and Action: A Social Cognitive Theory". - London: Pearson; 1984, 220p.

[52] Gonchar S. N. "Self-efficacy as a professional quality of future teachers-psychologists", in Pedagogical craftsmanship: materials internationally. Scientific Conf. (Moscow, April 2012). - Moscow: Buki-Vedi, 2012, pp. 250-253. (In Russian) 
[53] V. N.Kunitsina, N. V. Kazarinova, V. M. , "Interpersonal communication: a textbook for high schools". - St. Petersburg: Piter, 2001. 544p. (In Russian)

[54] M.Csikszentmihalyi, K. Rathunde, "The psychology of wisdom", in The psychology of wisdom. Sternberg R. J. (ed.). - New York, $.1989, \mathrm{pp} / 5-25$.
[55] W. C. Schutz, "Elements of encounter". - Big Sur, CA : Joy Press. 1973, 380p.

[56] F. Tochon, "Deep Education", in Educaçao, Sociedade \& Culturas, 2012, vol. 33, pp. 234-245. 